\title{
O MARKETING CULTURAL COMO ELEMENTO DE DIFERENCIAÇÃO: O CASE “BRADESCO - ESPETÁCULO COMO MENSAGEM"
}

\author{
The cultural marketing as an element of differentiation: the case "Bradesco - \\ spectacle as message"
}

\section{El marketing cultural como elemento de diferenciación: el caso "Bradesco - espetáculo como mensagem"}

\author{
Flavi Ferreira Lisboa Filho ${ }^{1}$ \\ Julia Munareto Leal ${ }^{2}$
}

\section{Resumo}

Propõe-se neste artigo uma pesquisa bibliográfica com a apresentação de conceitos e definições sobre o tema marketing cultural com vistas à comunicação organizacional. Para contextualizar o apanhado teórico apresenta-se o caso do Banco Bradesco, que iniciou uma reestruturação geral a fim de legitimar a adoção de um novo conceito, o de "banco completo". São descritas algumas ações de marketing cultural adotadas, que serviram como elemento de diferenciação para o Banco.

Palavras-chave: marketing cultural, comunicação organizacional, diferenciação.

\begin{abstract}
This article proposes a bibliographic search presenting concepts and definitions about the cultural marketing theme in order to organizational communication. To contextualize the theoretical summary it is presented the case of the Banco Bradesco, which started a general restructuration to legitimize the adoption of a new concept: "full bank". It is described some cultural marketing actions taken, which served as the differentiator for the Bank.
\end{abstract}

Keywords: cultural marketing, organizational communication, differentiation.

\footnotetext{
${ }^{1}$ Professor no Programa de Pós-Graduação em Comunicação e no Departamento de Ciências da Comunicação da Universidade Federal de Santa Maria - UFSM. Doutor em Ciências da Comunicação pela Universidade do Vale do Rio dos Sinos. Pesquisador líder do Grupo de Pesquisa Estudos culturais e audiovisualidades. E-mail: flavilisboa@gmail.com (55-99635050)

${ }^{2}$ Mestre pelo Programa de Pós-Graduação em Comunicação da UFSM - linha Mídia e Identidades Contemporâneas. Graduada em Relações Públicas pela UFSM. E-mail: juliaml_rp@ yahoo.com.br
} 
O marketing cultural como elemento de diferenciação: o case "bradesco -

espetáculo como mensagem"

de Flavi Ferreira Lisboa Filho e Julia Munareto Leal

\section{Resumen}

Propone se en este artículo una investigación bibliográfica con la presentación de conceptos y definiciones sobre el tema marketing cultural con vistas a la comunicación organizacional. Para contextualizar el aporte teórico presentase el caso del Banco Bradesco, que inició una reestructuración general a fines de legitimar la adopción de un nuevo concepto, lo de "banco completo". Son descriptas algunas acciones de marketing cultural adoptadas, que servirán como elemento de diferenciación para el Banco.

Palabras-clave: marketing cultural, comunicación organizacional, diferenciación.

\section{INTRODUÇÃO}

Este artigo tem o propósito de verificar se a utilização de ações de Marketing Cultural pelo Banco Bradesco contribuiu para a sua reestruturação. Primeiramente pode-se falar que o foco deste estudo é o de conceituar e entender o Marketing Cultural e a Comunicação Organizacional por meio de uma revisão teórica de autores que colaboram para explicar esta temática.

Além da pesquisa teórica acerca dos temas apresentados, tomamos como base para esta pesquisa o case "Bradesco: Espetáculo Como Mensagem" preparado por Rosilene Marcelino sob orientação do Prof. Francisco Gracioso. Toma-se como exemplo a matéria que aborda o case do Banco Bradesco de 2006, ano em que o Banco, que aqui figura como objeto de análise, investiu no patrocínio e associou sua marca a um espetáculo de grande repercussão no País: o 'Saltimbanco' do Cirque Du Soleil. A campanha do Banco buscava abranger desde a mudança da logomarca corporativa, a segmentação de públicos, o ajuste de produtos e serviços específicos para cada público, até se chegar à definição de um posicionamento e, conseqüentemente, ao alinhamento das comunicações mercadológica e institucional.

Com seus processos estruturados, a instituição entendeu que havia chegado o momento em que tais mudanças deveriam ser comunicadas e percebidas pela população em geral. O novo posicionamento adotado foi o de "Bradescompleto", que permeou de maneira predominante, toda a comunicação realizada pelo banco nos últimos anos e teve seu auge ao associar a marca Bradesco com a do Cirque du Soleil. Dessa forma, entre os anos 2006 e 2007, optou-se trabalhar o universo do lúdico e do entretenimento. 
O marketing cultural como elemento de diferenciação: o case "bradesco espetáculo como mensagem"

de Flavi Ferreira Lisboa Filho e Julia Munareto Leal

De acordo com Luca Cavalcanti (2006), diretor de marketing do Banco Bradesco, assim que o conceito "Bradescompleto" tornou-se o posicionamento do banco foi delineado um planejamento, pensado de forma que o Bradesco, junto com o posicionamento de completo, passasse a ter uma relevância diferenciada na mente do público em geral.

Com base no que foi exposto, pode-se dizer que os dois eixos deste estudo são o do marketing cultural e o da comunicação organizacional. O primeiro aparece evidenciado através do patrocínio do espetáculo Saltimbamco pelo Banco, fato que está baseado na divulgação de ações que contribuíram para a comunicação da nova estruturação desejada pela direção da empresa. Com a proposta de associar sua marca a este espetáculo, o Bradesco entrou no universo do Cirque du Solei. A partir de uma analogia entre seus valores e os do Cirque e a força e a experiência da marca Bradesco, chegou-se a um conjunto de elementos que estiveram por trás de toda a comunicação realizada no período. Houve, então, o alinhamento entre as campanhas institucional e mercadológica que ganharam as mídias impressa e audiovisual.

Neste contexto é que a comunicação midiática ganha espaço. Embora não tenhamos o objetivo de nos aprofundar teoricamente em seu estudo é imprescindível citá-la aqui, já que ela aparece ao se verificar a forma como o Banco divulgou o patrocínio do espetáculo e apareceu para o público em geral. A partir daí tem-se o segundo objetivo: o de identificar os principais meios de comunicação utilizados pelo Bradesco para divulgar o patrocínio do espetáculo cultural Saltimbanco.

É importante ressaltar que não almejamos analisar neste momento como as ações de marketing cultural centradas no espetáculo e veiculadas em meios de comunicação contribuíram para a redefinição da comunicação organizacional do Banco. Identificamse as ações e se descrevem os meios de comunicação utilizados na campanha. A justificava que baliza este trabalho centra-se em grande parte pelos elos teóricos que são traçados, relacionando-os com o case do Bradesco, com intuito de destacar a importância do marketing cultural e da comunicação organizacional no cenário analisado e também nos dias de hoje, já que as empresas são compelidas a buscar formas criativas e inovadoras de aparecer perante seus públicos.

Para isso, se procedeu a pesquisa bibliográfica, uma das fases mais importantes do trabalho, com base nos principais autores que tratam do tema Marketing Cultural e Comunicação Organizacional, para que se pudesse tomar conhecimento daquilo que já 
O marketing cultural como elemento de diferenciação: o case "bradesco -

espetáculo como mensagem"

de Flavi Ferreira Lisboa Filho e Julia Munareto Leal

foi abordado sobre o assunto. Lakatos e Marconi (1996: 66) afirmam que a finalidade da pesquisa bibliográfica "é colocar o pesquisador em contato direto com tudo que foi dito, escrito ou filmado sobre determinado assunto". A importância disso é desenvolver uma noção global da forma como o assunto vem sendo abordado, o que vai contribuir, posteriormente, na forma do pesquisador se posicionar frente ao tema.

Então, através da pesquisa bibliográfica desenvolvida, entende-se o marketing cultural como uma importante estratégia de divulgação para empresas, podendo vir a contribuir para sua diferenciação perante à sociedade e aos públicos que pretendem atingir. Posteriormente, se analisou o case "Bradesco: Espetáculo como Mensagem" através do qual pode ser constatado que a utilização de ações de marketing Cultural pelo Banco foi essencial para sua reestruturação.

\section{REFLEXÕES SOBRE MARKETING CULTURAL}

A cultura, termo com as mais diversas acepções, pode ser ilustrada como uma categoria conceitual que implica duas dimensões: a social e a histórica. A cultura como ação criadora do homem é a sua expressão essencial, enquanto que ele se realiza criando sua obra e comunicando intencionalmente aos outros essa criação. Por isso a cultura exprime o processo histórico do relacionamento do homem com o real e da sua realização no tempo e no espaço (PERUZZOLO, 2006). O homem cria, produz, acumula experiências e as partilha socialmente, isso como modo de suprir alguma carência - possivelmente, a de interação social -, onde a cultura é a resposta à necessidade de sobrevivência, de adaptação ao meio, de criação e gestão da própria vida. A Marilena Chauí (2008:21) define a cultura a partir de três traços principais:

Em primeiro lugar, é trabalho, ou seja, movimento de criação do sentido, quando a
obra de arte e a de pensamento capturam a experiência do mundo dado para
interpretá-la, transcendê-la e transformá-la-é a experimentação do novo. Em segundo
lugar, é a ação para dar a pensar, dar a ver, dar a refletir, a imaginar e a sentir o que
se esconde sobre as experiências vividas ou cotidianas (...) Em terceiro, em uma
sociedade de classes, de exploração, dominação e exclusão social a cultura é um
direito do cidadão, direito de acesso aos bens e obras culturais, direito de fazer cultura
(...)

Neste contexto em que se fala sobre o direito de ter acesso à cultura a autora menciona também o direito de "fazer cultura". Termo que pode ser associado à idéia de 
O marketing cultural como elemento de diferenciação: o case "bradesco -

espetáculo como mensagem"

de Flavi Ferreira Lisboa Filho e Julia Munareto Leal

produzir cultura, trazida neste artigo através da produção cultural e mais especificamente, do marketing cultural. A produção cultural pode ser vista como uma atividade de planejamento, organização e execução de ações, eventos e projetos culturais, que pode destinar diversos tipos de atividades a diferentes públicos.

O Marketing Cultural, com uso delimitado através do patrocínio de eventos culturais, vem crescendo de forma expressiva no Brasil e no mundo. De uma maneira direta pode-se defini-lo como o conjunto de ações de marketing que se utiliza do patrocínio de atividades culturais e projeta/divulga a marca de determinada organização, quando essa tem seu nome associado à atividade cultural em questão. Já a atividade de patrocínio pode ser caracterizada como

Uma relação de troca do tipo prestação/contratação. O patrocinador fornece recursos e o patrocinado fornece contraprestações que favorecem, direta ou indiretamente os objetivos de marketing do primeiro. O patrocínio é acordado em função de uma decisão estratégica da empresa, tendo como ponto de partida seu público-alvo (REIS e SANTOS, 1996:19)

Os mesmos autores trazem Cogill que enfatiza o fato de o patrocínio muitas vezes ser marketing, já que ao praticá-lo as empresas esperam atingir resultados tangíveis como maior visibilidade e conhecimento de sua marca, publicidade, e até mesmo resultados comerciais concretos (COGILL apud REIS e SANTOS, 1996:20). Sandler e Shani entendem o patrocínio como

(...) a provisão de recursos por uma organização, diretamente para um evento ou atividade, em troca de uma associação direta com este evento ou atividade. A organização provedora pode então usar essa associação direta para atingir seus objetivos corporativos, de marketing ou de comunicações. (SANDLER e SHANI apud REIS e SANTOS, 1996:21)

De acordo com Nussbaumer (2000:30) o patrocínio está vinculado a objetivos de vendas das empresas, com intenções comerciais. A autora vê a atividade como uma técnica de comunicação de duplo grado, com foco direto e indireto. O patrocinador visa conquistar um público direto ao fixar sua marca sobre os espaços publicitários que lhe oferece o patrocinado, mas, sobretudo, um público indireto através da divulgação na mídia de um evento do qual participa.

Por sua vez, o marketing cultural pode ser definido de acordo com Fisher (2002), como um recurso para fixar a marca da organização por meio das mais diversas ações 
O marketing cultural como elemento de diferenciação: o case "bradesco -

espetáculo como mensagem"

de Flavi Ferreira Lisboa Filho e Julia Munareto Leal

culturais, reforçando as relações institucionais com poderes públicos e apresentando a empresa como um agente sociocultural. Sendo assim, podemos afirmar que patrocínio cultural e marketing cultural são atividades semelhantes, que tem em sua prática os mesmos objetivos: promover determinada marca ou organização em troca do apoio cultural realizado pela mesma.

Dessa forma, o Marketing Cultural passa a ser um instrumento qualificador ao buscar associar a organização a expressões e manifestações artísticas culturais. Seu uso parece ser adequado tanto no desenvolvimento de uma relação entre um produto, uma marca ou um serviço e seus consumidores, quanto no desenvolvimento de uma relação entre uma empresa e a sociedade já que o investimento em evento cultural fixa a imagem da marca como uma empresa atenta aos interesses da comunidade. Logo,

O projeto cultural tem a capacidade de transportar uma informação de um universo, que é o público que consome aquele produto cultural, para outro universo, que é o público consumidor do produto ou do serviço da empresa patrocinadora (ALAMEDA apud COSTA, 2004: 36).

Então, em um cenário altamente competitivo, onde é destaque o constante aumento da oferta de novos produtos e serviços, o investimento em cultura passa a ser uma forma de diferenciar a marca na mente dos stakeholders da organização. Reis (2003: 04) vai ao encontro desta afirmação ao apresentar o Marketing Cultural como um processo que "se usa da cultura como base e instrumento para transmitir determinada mensagem (e, a longo prazo desenvolver um relacionamento) a um público específico, sem que a cultura seja a atividade-fim da empresa."

Nesse sentido, o uso do marketing cultural vem possibilitando às empresas se diferenciarem de outras, contornando assim dificuldades impostas pela competitividade do mercado. Isso porque ao associar sua marca a determinado evento que reúna um público específico no qual a mesma tenha interesse, a organização se comunica diretamente com este público. Entre as vantagens que se pode atingir ao patrocinar um evento cultural, Cogill, citado por Reis e Santos (1996), destaca o reforço ou aprimoramento da imagem corporativa, maior conhecimento da marca ou empresa, construção da credibilidade por meio da transferência de atributos relacionados ao evento patrocinado à empresa patrocinadora. Os autores reforçam ainda que "as vantagens dos patrocínios são limitadas apenas pela criatividade do próprio patrocinador" (COGILL apud REIS e SANTOS, 1996:23). 
O marketing cultural como elemento de diferenciação: o case "bradesco espetáculo como mensagem"

de Flavi Ferreira Lisboa Filho e Julia Munareto Leal

Com isso entende-se que o marketing cultural é uma alternativa de comunicação bastante válida para as organizações, quando se observa os benefícios que pode trazer para a sociedade e assim, para a construção de uma imagem positiva perante a mesma. No Brasil, o Marketing Cultural "pode ser definido como mais um instrumento de comunicação junto a determinado consumidor." (COSTA, 2004: 35). Ao encontro disso Nussbaumer (2000: 29) diz que as empresas dedicam-se agora a uma política de comunicação mais aberta no que concerne ao público em geral e não mais somente em torno de consumidores eventuais. Isso devido à consciência de sua função social, além de sua tradicional função de produção. Assim, a comunicação, mais especificamente a organizacional, ganha espaço e é termo chave na nesta investigação.

\title{
3. COMUNICAÇÃO ORGANIZACIONAL: NOÇÕES CONCEITUAIS
}

O aumento da complexidade no relacionamento das empresas com seus públicos se intensificou com o passar do tempo, principalmente nos últimos anos, o que resultou na valorização e no crescimento da atividade de comunicação organizacional. Ela engloba toda a comunicação estruturada que uma empresa ou instituição mantém com seus stakeholders, que direta ou indiretamente são afetados ou beneficiados pela atividade organizacional. Kunsch (1997) apresenta um conceito de Goldhaber ao abordar a comunicação organizacional

\begin{abstract}
A comunicação organizacional é considerada como um processo dinâmico por meio do qual as organizações se relacionam com o meio ambiente e por meio do qual as subpartes da organização se conectam entre si. Por conseguinte, a comunicação organizacional pode ser vista como o fluxo de mensagens dentro de uma rede de relações interdependentes (GOLDHABER apud KUNSCH, 1997: 68).
\end{abstract}

Uma comunicação bem estruturada é fundamental para qualquer organização, é ela que vai viabilizar o funcionamento do sistema organizacional, relacionando departamentos e setores entre si e com a direção. E, além de estabelecer esta relação dentro da organização, pode proporcionar também, o contato com outras organizações, podendo resultar em um bom relacionamento entre elas e até a formação de parcerias, o que é considerado um diferencial no competitivo cenário do mercado atual. Para Marín apud Pinho (2006: 280), 
O marketing cultural como elemento de diferenciação: o case "bradesco -

espetáculo como mensagem"

de Flavi Ferreira Lisboa Filho e Julia Munareto Leal

A idéia básica é que uma organização nunca está isolada, mas sim funciona em um campo interorganizacional, e deve coordenar, portanto, suas atividades com outras entidades com as quais compartilhe algum tipo de interesse. Uma empresa produtora de determinados bens dependerá de outras empresas que fornecem matérias primas, serviços ou informação, ou que comercializam os seus produtos, além de outras organizações públicas, municipais, estaduais ou federais.

Diante disso pode-se afirmar que a interdependência entre as organizações tem aumentado cada vez mais, assim como a necessidade de comunicação entre elas. Pinho (2006) reafirma que é importante estabelecer e manter boas relações de comunicação entre organizações, bem como de uma organização com as entidades e indivíduos dentro de seu entorno, desenvolvendo canais adequados, diminuindo as diferenças interculturais e promovendo práticas éticas.

Além disso, quando a empresa não consegue comunicar corretamente, de maneira coerente, aquilo que espera e pretende alcançar, diminui a probabilidade de atingir os resultados esperados. Ao contrário disso, quando a comunicação é bem estruturada, gera melhores possibilidades de relacionamento com os diversos públicos. No âmbito externo, é fundamental elaborar um processo de comunicação organizacional que esteja em sintonia com a sociedade, com todos os esforços focados visando à construção de uma reputação positiva e à diferenciação diante do concorrido mercado atual.

Ora, é certo que a diferenciação do produto da organização tem sua importância, e um bom processo de comunicação organizacional pode contribuir para sua positivação, atribuindo acréscimo de qualidade e valoração. No entanto, é preciso pensar além do negócio da empresa para poder agregar valor à sua imagem. Essa, segundo Baldissera (2000:13), “é construída a partir de alguns traços de identidade que são comunicados". De acordo com o referido autor, a identidade de cada organização, possui o seu conjunto de traços, que permitem um reconhecimento da mesma como sendo única. Pode-se dizer que é a personalidade da organização, apresentada toda vez que ela se mostra (como unidade e como produto/serviço). Assim, como reforça Argenti (2006: 82)

Uma vez que todos os setores hoje em dia estão focados na competitividade global e que as empresas estão tentando driblar a escassez de recursos, a identidade e a imagem de uma organização podem se tornar o único traço distintivo entre uma empresa $e$ outra. 
O marketing cultural como elemento de diferenciação: o case "bradesco espetáculo como mensagem"

de Flavi Ferreira Lisboa Filho e Julia Munareto Leal

Assim sendo, salientamos que, de acordo com Pinho (2006), a comunicação organizacional tem uma relação estreita com a criação desta identidade organizacional, isso porque, quando ela é comunicada, influencia diretamente na construção do sentido de valor que a organização estabelece para com seus públicos e em consequiência disso se dá a consolidação de uma imagem corporativa que deve ser compatível com as exigências do mercado.

Não se pretende aprofundar no estudo de identidade neste trabalho, mas uma breve abordagem do tema se faz necessária pelo fato de que assim como a comunicação, a cultura exprime a identidade organizacional. É a partir dela, quando divulgada em ações de comunicação, podendo estas ações envolver o marketing cultural, por exemplo, que os stakeholders formam uma imagem da organização. A propósito Fossá (1999:213) afirma que,

\begin{abstract}
As empresas modernas (...) precisam adaptar suas estruturas de comunicação para atenderem às expectativas e requerimentos de seus públicos, conhecerem a zona de carência que leva os receptores, os sujeitos, a buscarem esclarecimentos, e, ao mesmo tempo produzirem interrogações, pistas, interpretações acerca de seu mundo individual e coletivo.
\end{abstract}

No caso do Banco Bradesco foi isso que se percebeu a partir da divulgação da prática do marketing cultural para públicos interno e externo. Uma ação positiva visto que, nos dias de hoje, ainda que muitas empresas busquem adaptar estruturas comunicacionais para atender os anseios dos diversos públicos, a realidade da comunicação organizacional envolve obstáculos. Segundo Kunsch (1997: 88) “as empresas têm um discurso, mas ainda não têm uma prática. Elas sabem fazer e vender produtos, mas não conhecem exatamente seu papel, o que é construir uma imagem, o que é opinião pública e o que esta quer delas."

O que falta na prática é um entendimento maior de tudo que a comunicação envolve. Não basta afirmar e reafirmar que ela é importante. O reconhecimento desta importância já aconteceu, pelo menos no discurso de muitas organizações ele já é considerado. Mais do que isso, é preciso mostrar onde a comunicação organizacional influi e como pode esclarecer questões muitas vezes confusas dentro das empresas. É aí que se apresenta o case "Bradesco: Espetáculo como mensagem" aonde se percebe as mudanças ocorridas internamente na organização e a necessidade em comunicá-las de forma que passassem a ser percebidas e entendidas pelo público em geral. 
O marketing cultural como elemento de diferenciação: o case "bradesco espetáculo como mensagem"

de Flavi Ferreira Lisboa Filho e Julia Munareto Leal

É necessário que aqueles que participam da organização tomem conhecimento destes elementos fundamentais, pois a comunicação é uma relação intersubjetiva que se baseia nas experiências daqueles que dela participam, fazendo apelo à experiência de cada um e do indivíduo com o todo. Sendo assim, foi através da comunicação midiática que o Banco Bradesco resolveu divulgar sua reestruturação interna e comunicar que a instituição contemplava pioneirismo, segmentação e diferenciação.

\section{APONTAMENTOS SOBRE O CASE "BRADESCO: ESPETÁCULO COMO MENSAGEM"}

De acordo com o site do Banco Bradesco, sua trajetória teve início em 1943, na cidade de Marília - São Paulo, local onde inaugurou sua primeira sede. Nesta época buscava atrair pessoas de poucos recursos. Três anos depois o Banco já tem sua sede na capital paulista e passou a oferecer outros serviços aos seus clientes. Nos anos seguintes o Banco atingiu uma expansão em relação à sua estrutura, tendo inaugurado novas sedes em outras cidades do Brasil.

Já em 1956 o Banco se tornou pioneiro em ações de responsabilidade social e nos anos que seguiram inovou com a implementação de computadores em suas agências e disponibilização de cartões de créditos aos clientes. No ano 2000, um marco especial na história do Banco: a fundação Bradesco atinge mil alunos. Destacando-se no mercado nacional de varejo, o Bradesco, atualmente, está entre os líderes de diversos segmentos como o atendimento a micro, pequenas e médias empresas.

Conforme já foi apresentado na introdução deste texto, o conceito "Bradescompleto" tornou-se a diferenciação do Banco entre 2006 e 2007 e isso precisou ser comunicado ao seu público de modo que comunicação organizacional e mercadológica estivessem alinhadas. Assim, após todo processo de reposicionamento, o Bradesco buscou inovar e se destacar de empresas do mesmo segmento que o seu e por isso, buscou associar sua marca a algo diferenciado e lúdico, o que foi possível através do patrocínio de um evento cultural. Com esta idéia, o Bradesco objetivava trazer pela primeira vez o Cirque du Soleil ao Brasil. No ano de 2006, o espetáculo em destaque produzido pelo Grupo circense era o "Saltimbanco". Depois de efetivada a parceria, o Banco passou a divulgar sua marca fazendo alusão ao espetáculo e buscando associar seus serviços aos valores adotados pelo Cirque. 
O marketing cultural como elemento de diferenciação: o case "bradesco espetáculo como mensagem"

de Flavi Ferreira Lisboa Filho e Julia Munareto Leal

No case "Bradesco: Espetáculo como Mensagem" encontram-se alguns exemplos das associações feitas entre o Banco e o evento cultural como, por exemplo: o Bradesco atinge toda a população brasileira, o Cirque é o circo mais abrangente do planeta; o Bradesco foi pioneiro da sua categoria em diversas iniciativas, o Cirque foi inovador e reinventou o Circo; o Banco, do ponto de vista empresarial, é cada vez mais eficiente, o Cirque, por sua vez, tem como características a excelência técnica, visual e performática; em constante crescimento o Bradesco alcançou em 2005 o maior lucro entre os bancos brasileiros, o Cirque é um negócio de excelentes resultados; o Bradesco foi eleito o melhor Banco do Brasil pela revista The Banker, o Cirque é reconhecido como o melhor circo do mundo.

De acordo com o case, a campanha teve o objetivo de reforçar a imagem institucional e elevar a percepção de qualidade de serviço, atendimento e produtos do banco, mas tudo isso, mantendo a forma lúdica e sem interromper o entretenimento. Foram três os veículos de comunicação utilizados pelo Banco para divulgar sua campanha, apoiada no marketing cultural: comerciais de televisão, anúncios em revistas e spots para rádio.

As apresentações do Cirque figuravam nas propagandas (veiculadas nas principais emissoras do país) de maneira central, sempre preservando a imagem dos artistas e as suas performances. As chamadas do filme falavam dos novos serviços e vantagens do Banco, comparados com as características do Cirque, que sempre figurou como protagonista. A marca do Bradesco aparecia nos comerciais ora com mais destaque ora com menos, na lateral inferior direita da tela ou na parte inferior do vídeo, de modo que o foco permanecesse sempre no artista e sua performance. Após analogias entre os novos serviços do Banco e características das apresentações do Cirque, a chamada que encerrava os VTs era sempre "Se o Cirque du Soleil fosse um banco, ele seria completo".

O comercial veiculou em 49 programas de TV. Outro meio de comunicação utilizado foi o rádio, através da transmissão de spots. Por fim, o Banco publicou anúncios de mídia impressa nas oito maiores revistas do Brasil. Apropriando-se do conteúdo do Cirque du Soleil em sua comunicação, criou anúncios utilizando os artistas e seus atos nos espetáculos como malabarismo, equilíbrio, acrobacias e relacionava as qualidades destas habilidades com as novas características do Banco. O conceito 
O marketing cultural como elemento de diferenciação: o case "bradesco -

espetáculo como mensagem"

de Flavi Ferreira Lisboa Filho e Julia Munareto Leal

"Bradescompleto" foi trazido em todas as peças, enfatizando mais uma vez a reestruturação da empresa.

Além da campanha em veículos de comunicação o banco beneficiou seus clientes, pessoas jurídicas, autoridades governamentais, funcionários e crianças atendidas pela Fundação Bradesco com ações promocionais que sorteavam ingressos, proporcionavam sessões fechadas exclusivas, pré-venda de ingressos exclusiva para clientes e o pagamento exclusivo com cartões do banco.

Ou seja, utilizou o patrocínio do espetáculo cultural para estar em contato com seus públicos, fidelizando-os e simultaneamente comunicando a eles a nova fase. Dessa forma, o Bradesco conseguiu apresentar a reformulação de seus serviços quebrando a impressão de grandeza que o Banco trazia anteriormente e, relacionando todos seus serviços ao espetáculo cultural Cirque du Soleil, o que foi possível com ações de marketing cultural utilizadas e exploradas de diversas maneiras por várias áreas do banco.

\section{CONSIDERAÇÕES}

Toda organização tem um conjunto de comportamentos e saberes, que no decorrer de sua atuação vai sofrendo adaptações e modificações em sua estrutura. Através da análise teórica percebe-se que atualmente algumas empresas buscam formas diferentes para divulgar sua imagem e, no caso do objeto de pesquisa, para se diferenciar frente aos seus públicos. Foi com objetivo de alinhar comunicação organizacional com a mercadológica e divulgar sua reestruturação que o Banco Bradesco se valeu do marketing cultural e apareceu entre 2006 e 2007 nos mais diversos veículos de comunicação midiática do país.

Em relação a este diferencial proporcionado pela prática do marketing cultural, Nussbaumer (2000) afirma que comunicar-se de maneira diferenciada, apoiando ou se utilizando da cultura parece ser uma das soluções encontradas para concorrer em um mercado já resistente à publicidade convencional. O marketing cultural, nesse contexto, firmou-se como um instrumento de comunicação empresarial diferenciado e convincente na busca de uma identidade favorável às empresas junto a seus públicos.

A importância em comunicar a prática do marketing cultural se mostra no objetivo do alinhamento das comunicações expresso pelo Bradesco. Percebe-se uma 
O marketing cultural como elemento de diferenciação: o case "bradesco espetáculo como mensagem"

de Flavi Ferreira Lisboa Filho e Julia Munareto Leal

preocupação do Banco em comunicar ao público em geral suas modificações e interesses de uma forma impactante. De acordo com Fossá (1999: 184) “a comunicação empresarial deve estar incorporada à atividade da organização levando em consideração interesses institucionais, comunitários e dos grupos a quem a instituição serve.”.

Levando em conta estes interesses pode-se concluir e avaliar de maneira positiva as ações do Banco, que de forma integrada propuseram peças para os mais diversos veículos de comunicação. A campanha do Banco soube entender o espírito do Cirque e através de um projeto eficaz utilizou de tudo que o espetáculo oferecia para aparecer a seus públicos. De acordo com o case "Bradesco: Espetáculo como Mensagem" uma forma de mensurar a repercussão positiva desta campanha que usou do marketing cultural foi a lembrança da marca pelo público em geral. Através de pesquisa realizada e cedida pela agência responsável pela campanha, a marca Bradesco figurou entre as dez marcas mais lembradas pelo consumidor em 2006. Além disso, o comercial Cirque du Soleil foi apontado como um dos comerciais preferidos pelo público por dois meses consecutivos $^{3}$. Também o Bradesco encomendou uma pesquisa logo após a veiculação dos comerciais, anúncios e spots e nela os resultados apontaram um crescimento na avaliação dos atributos da imagem.

Com isso compreende-se que a utilização de ações de Marketing Cultural pelo Banco Bradesco foi essencial para a sua reestruturação e o entendimento pelo público, o que refletiu nos resultados positivos das pesquisas realizadas. Após identificar os principais veículos de comunicação utilizados para veiculação da campanha - TV, rádio e anúncios impressos nas principais revistas do Brasil - que divulgou o patrocínio do espetáculo cultural "Saltimbanco", chega-se a um conjunto de elementos que estiveram por trás de toda a comunicação realizada de maneira integrada, indo ao encontro de nossas expectativas em relação ao alcance dos objetivos traçados inicialmente pelo Banco.

\section{REFERÊNCIAS BIBLIOGRÁFICAS}

ARGENTI, Paul P. Comunicação empresarial: a construção da identidade, imagem e reputação. Rio de Janeiro: Elsevier, 2006. ${ }^{3}$ Fonte: Meio e Mensagem de 28 de agosto e 19 de setembro de 2006. Informação obtida do case
"Bradesco: Espetáculo como mensagem". 
O marketing cultural como elemento de diferenciação: o case "bradesco espetáculo como mensagem"

de Flavi Ferreira Lisboa Filho e Julia Munareto Leal

BALDISSERA, Rudimar. Comunicação organizacional: o treinamento de recursos humanos como rito de passagem. São Leopoldo: Ed. Unisinos, 2000.

CHAUÍ, Marilena. Cultura e democracia: crítica e emancipação. Revista Latinoamericana de Ciências Sociais. Ano 1, no. 1 (jun. 2008- ). Buenos Aires: Ed. CLACSO, 2008.

COSTA, Ivan Freitas da. Marketing cultural: o patrocínio de atividades culturais como ferramenta de construção de marca. São Paulo: Atlas, 2004.

FISHER, Micky. Marketing cultural: legislação, planejamento e exemplos práticos. São Paulo: Global, 2002.

FOSSÁ, Maria Ivete Tevisan. Os novos desafios da comunicação empresarial na era da qualidade. Cadernos de Comunicação. Universidade Federal de Santa Maria. Centro de Ciências Sociais e Humanas. Faculdade de Comunicação Social. Santa Maria: n.3, 1999.

KUNSCH, Margarida Maria K. Relações públicas e modernidade: novos paradigmas na comunicação organizacional. 4. ed. São Paulo: Summus, 1997.

LAKATOS, Eva Maria; MARCONI, Marina de Andrade. Metodologia do trabalho científico. São Paulo: Atlas, 1996.

MALVESTITI, Fernanda Pacheco de Moraes Guevara; CAETANO, Kati. Identidades visuais e estratégias enunciativas: a logomarca corporativa do Bradesco. Universidade Tuiuti do Paraná, Curitiba, PR. Intercom - Sociedade Brasileira de Estudos Interdisciplinares da Comunicação IX Congresso de Ciências da Comunicação na Região Sul - Guarapuava - 29 a 31 de maio de 2008.

MARCELINO, Rosilene; GRACIOSO, Francisco Gracioso. Bradesco: espetáculo como mensagem. Revista ESPM. São Paulo. Vol. 14, ano13, edição no 4 - julho/ago 2007:26-35.

NUSSBAUMER, Gisele Marchiori. O mercado da cultura em tempos (pós) modernos. Santa Maria: Ed. da UFSM, 2000.

PERUZZOLO, Adair Caetano. A comunicação como encontro. Bauru, SP: EDUSC, 2006.

PINHO, J.P. Comunicação nas organizações. Viçosa: Ed. Ufv, 2006.

REIS, Ana Carla Fonseca. Marketing cultural e financiamento da cultura: teoria e prática em um estudo internacional comparado. São Paulo: Pioneira Thomson Learning, 2003. 
O marketing cultural como elemento de diferenciação: o case "bradesco espetáculo como mensagem"

de Flavi Ferreira Lisboa Filho e Julia Munareto Leal

REIS, Ana Carla Fonseca; SANTOS, Rubens da Costa. Patrocínio e mecenato: ferramentas de enorme potencial para as empresas. Revista de Administração de Empresas, São Paulo, v.36, n.2: 17-25, Abr./Mai./Jun. 1996.

SANTOS, Jair Ferreira. O que é pós-moderno? Ed. Brasieliense, 1987. Banco Bradesco. Disponível em <http // www.bradesco.br.> Acesso em dezembro de 2010.

Artigo submetido: 27/03/2013

Artigo aprovado: 25/11/2013 